\title{
Agrobacterium VirD2-Binding Protein Is Involved in Tumorigenesis and Redundantly Encoded in Conjugative Transfer Gene Clusters
}

\author{
Minliang Guo, Qingming Hou, Choy L. Hew, and Shen Q. Pan \\ Department of Biological Sciences, National University of Singapore, Singapore 117543
}

Submitted 25 February 2007. Accepted 14 May 2007.

\begin{abstract}
Agrobacterium tumefaciens can transfer oncogenic T-DNA into plant cells; T-DNA transfer is mechanistically similar to a conjugation process. VirD2 is the pilot protein that guides the transfer, because it is covalently associated with single-stranded T-DNA to form the transfer substrate $T$ complex. We used the VirD2 protein as an affinity ligand to isolate VirD2-binding proteins (VBPs). By pull-down assays and peptide-mass-fingerprint matching, we identified an $A$. tumefaciens protein designated VBP1 that could bind VirD2 directly. Genome-wide sequence analysis showed that $A$. tumefaciens has two additional genes encoding proteins highly similar to VBP1, designated $v b p 2$ and $v b p 3$. Like VBP1, both VBP2 and VBP3 also could bind VirD2; all three VBPs contain a putative nucleotidyltransferase motif. Mutational analysis of $v b p$ demonstrated that the three $v b p$ genes could functionally complement each other. Consequently, only inactivation of all three $v b p$ genes highly attenuated the bacterial ability to cause tumors on plants. Although $v b p 1$ is harbored on the megaplasmid pAtC58, $v b p 2$ and $v b p 3$ reside on the linear chromosome. The $v b p$ genes are clustered with conjugative transfer genes, suggesting linkage between the conjugation and virulence factor. The three VBPs appear to contain C-terminal positively charged residues, often present in the transfer substrate proteins of type IV secretion systems. Inactivation of the three $v b p$ genes did not affect the T-strand production. Our data indicate that VBP is a newly identified virulence factor that may affect the transfer process subsequent to T-DNA production.
\end{abstract}

Additional keywords: VirB; vir genes.

Agrobacterium tumefaciens is a gram-negative soilborne bacterium. It causes crown gall tumor disease in dicotyledonous plants by transferring a segment of DNA (T-DNA) from its Ti-plasmid to plant cells (Gelvin 2000; Zhu et al. 2000; Zupan et al. 2000). The T-DNA is delineated by 25-bp direct repeat sequences, which are called T-borders. Regardless of the sequence or origin, any DNA fragment placed between the two 25-bp direct repeats can be transferred into the plant cells and integrated into the host genome. In addition to its natural plant hosts, A. tumefaciens has been shown to transfer DNA to yeast (Bundock et al. 1995; Piers et al. 1996), fungal (Groot et al. 1998), and mammalian cells (Kunik et al. 2001) under laboratory conditions.

Corresponding author: Shen Q. Pan; Telephone: +65-6516-2977; Fax: +65-6779-5671; E-mail: dbspansq@nus.edu.sg
The T-DNA transfer process is triggered by plant wound signal compounds, such as some phenolic compounds and sugars. These signal compounds induce the expression of virulence (vir) genes; the Vir proteins encoded by the vir genes are essential for the processing, transfer, and eventual integration of the T-DNA into plant chromosome. The expression of the genes encoded on the T-DNA leads to crown gall tumor formation (Gelvin 2000, 2003; McCullen and Binns 2006; Tzfira and Citovsky 2006; Tzfira et al. 2000; Zupan et al. 2000).

VirD2 plays a crucial role in T-DNA transfer. In the presence of VirD1, VirD2 nicks T-DNA at the 25-bp direct repeat sequences of double-stranded (ds) Ti plasmid to produce the Tstrand (Filichkin and Gelvin 1993; Scheiffele et al. 1995; Yanofsky et al. 1986). Purified VirD2 alone can cleave a singlestranded (ss) T-border sequence in vitro (Jasper et al. 1994; Pansegrau et al. 1993). The VirD2-catalyzed nicking is site- and strand-specific (Jayaswal et al. 1987; Yanofsky et al. 1986). After the cleavage, VirD2 remains covalently associated with the $5^{\prime}$ end of the T-strand. Mutational analysis of VirD2 indicated that tyrosine 29 is required for the covalent association of VirD2 with the T-strand (Pansegrau et al. 1993; Vogel and Das 1992). VirD2 contains two distinct functional nuclear localization signals (NLSs). The monopartite NLS is located in the N-terminal region of the protein; the bipartite NLS resides in the C-terminal region. VirD2 also is postulated to direct the movement of the T-strand in a $5^{\prime}-3^{\prime}$ directional manner and target it to the plant cell nucleus (Howard et al. 1992; Tinland et al. 1992).

The 11 VirB proteins and VirD4 are involved in the biogenesis of the T-complex transfer apparatus, which is a member of the type IV secretion system (T4SS) family (Backert and Meyer 2006; Christie 2004; Christie et al. 2005). T4SS represents a growing class of evolutionarily conserved transporters that transfer DNA and proteins into a wide variety of organisms, including bacterial and eukaryotic cells (Backert and Meyer 2006; Christie et al. 2005). The VirB proteins are homologous to the transfer proteins essential for the conjugative transfer of bacterial plasmids and those essential for the secretion of the Bordetella pertussis toxin protein (Backert and Meyer 2006; Christie 2004; Christie et al. 2005; Lessl et al. 1992). VirB10 and VirB11 have homologs in the Dot virulence system of Legionella pneumophila, which exports protein substrates (Christie et al. 2005; Vogel et al. 1998). The virBencoded transport apparatus, the Tra systems of the broad host range plasmids, and the Dot virulence system of L. pneumophila also can promote the conjugative transfer of a common substrate, the non-self-transmissible IncQ plasmid RSF1010 (Backert and Meyer 2006; Beijersbergen et al 1992; Christie et al. 2005; Haase et al. 1995; Vogel et al. 1998). 
In order to identify any additional protein or proteins that may be involved in the T-DNA transfer, we chose the VirD2 protein as a "bait" to "fish out" bacterial proteins that can interact with VirD2. We identified an $A$. tumefaciens protein designated VirD2-binding protein (VBP)1 that could bind VirD2. Two genes encoding proteins highly similar to VBP1 also are found on the linear chromosome of A. tumefaciens and designated $v b p 2$ and $v b p 3$. To understand the role of these $v b p$ genes in $A$.

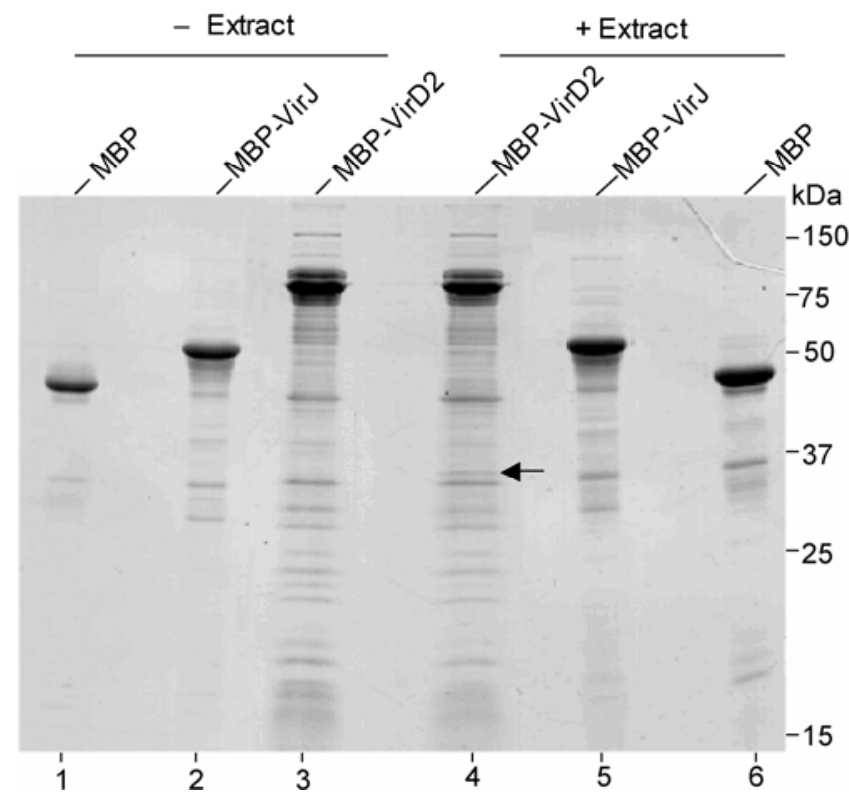

Fig. 1. Sodium dodecyl sulfate polyacrylamide gel electrophoresis (SDSPAGE) analysis of proteins pulled down by maltose-binding protein (MBP)-VirD2. Escherichia coli cells expressing MBP, MBP-VirJ, and MBP-VirD2 were extracted. The extracts were loaded onto amylose resin columns; the unbound proteins were washed away. As negative controls, MBP (lane 1), MBP-VirJ (lane 2), and MBP-VirD2 (lane 3) were eluted with maltose directly. For the pull-down assay, amylose resins bound with MBP-VirD2 (lane 4), MBP-VirJ (lane 5), and MBP (lane 6) were further incubated with the protein extract of acetosyringone-induced Agrobacterium tumefaciens cells. After washing, the bound proteins were eluted with maltose. Proteins were resolved by $12 \%$ SDS-PAGE gel and stained with Coomassie brilliant blue. The unique band protein is indicated by an arrow (lane 4). tumefaciens, we mutated three $v b p$ genes; a triple mutant of the three $v b p$ genes exhibited attenuated bacterial ability to cause tumors on plants. The VBP did not affect the T-strand production. These suggest that VBP is an additional virulence factor important for the transfer process subsequent to T-DNA production.

\section{RESULTS}

\section{Identification of VBP1.}

To identify additional bacterial proteins that may be involved in T-DNA processing and transfer, we fused VirD2 to maltosebinding protein (MBP); the MBP-VirD2 fusion protein was used as an affinity ligand to pull down VBPs from crude extracts of $A$. tumefaciens cells induced by acetosyringone (AS). One unique protein was present in the samples pulled down by MBP-VirD2 (Fig. 1, arrowed in lane 4) and not in the controls. We extracted the surrounding proteins of the pull-down samples from the gels and identified them using matrix-assisted laser desorption-ionization time-of-flight (MALDI-TOF) mass spectrometry (MS). We found that only the unique protein gave an apparent match with an A. tumefaciens protein: a hypothetical protein Atu5117 (accession no. AAL45807) in the University of Washington (UW) version of A. tumefaciens genome (Wood et al. 2001) or AAK90491 in the Cereon version (Goodner et al. 2001). All other identified proteins matched with MBP, VirD2 or VirJ, indicating that they are part of the ligands (data not shown).

This unique protein then was characterized as a putative VBP; a MALDI-TOF mass spectrometer was used to obtain the peptide mass map (Fig. 2). MS-Fit search of the peptide mass map indicated that the top two search hits had significantly higher molecular weight search (MOWSE) scores than other hits. Both of them indicated a molecular weight consistent with the unique protein. The corresponding proteins are encoded by an identical DNA sequence in the two genome versions (Goodner et al. 2001; Wood et al. 2001). The 12 main peptide masses (Fig. 2) matched with the calculated tryptic peptide masses from the top search hit (Fig. 3). Therefore, the MS-Fit results indicated an unambiguous identification of an A. tumefaciens protein that may bind to VirD2. Subsequently, we sequenced five peptides of tryptic digestion by quadrupole (Q)-TOF tandem mass spectrometry (MS/MS) to further con-

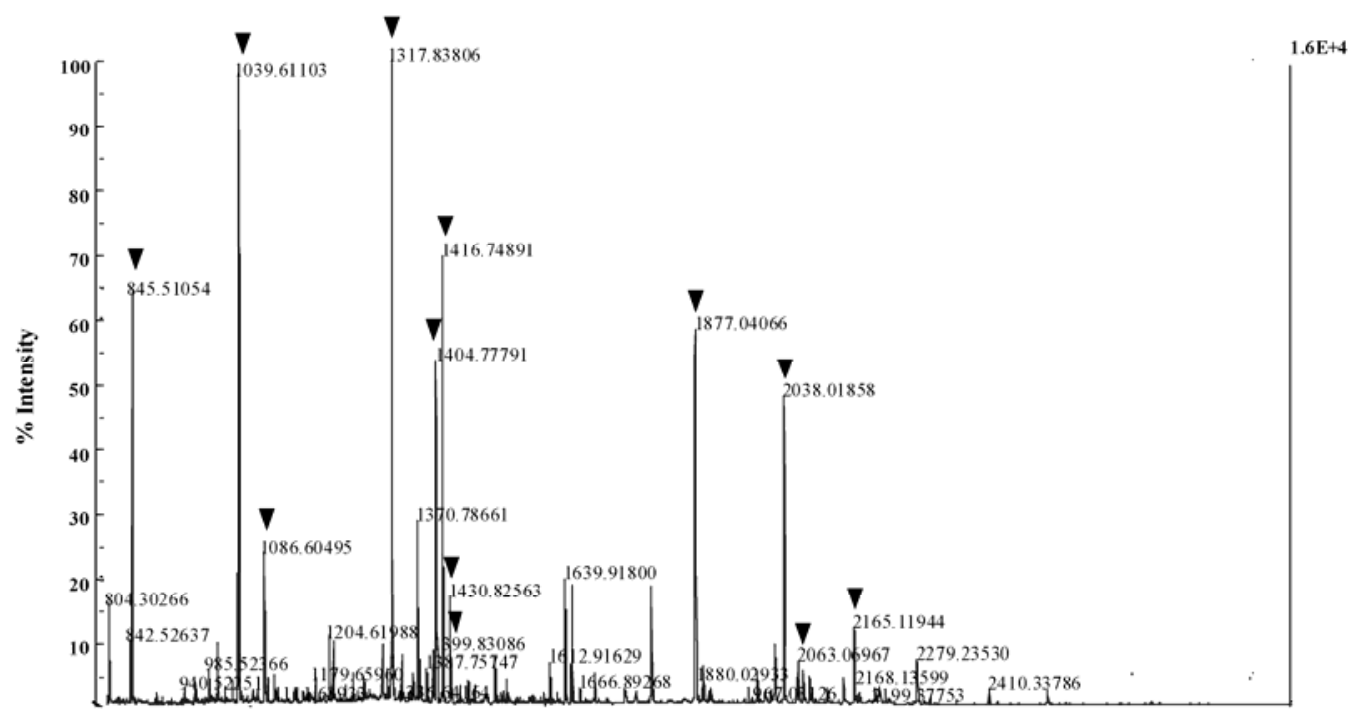

Fig. 2. MALDI time-of-flight (TOF) peptide mass map of a putative VirD2-binding protein. The unique protein from the MBP-VirD2 pull-down sample was excised from gel and in-gel digested by trypsin. The resulting peptides were analyzed using a MALDI-TOF mass spectrometer to obtain the mass map. Peptide peaks that corresponded to the calculated tryptic peptide masses of an Agrobacterium tumefaciens protein are indicated by triangles. 
firm the identification. The sequences of these five peptides matched $100 \%$ with the A. tumefaciens protein (data not shown). A peptide fragment matched exactly with the N-terminus of the top search hit, indicating that the start codon predicted by the UW genome version (Wood et al. 2001) is correct. We designated this protein VBP1.

\section{VBP homologs.}

When we conducted the BLAST search, we found that the A. tumefaciens genome encodes two additional proteins with similar amino acid sequences, Atu4860 (accession no. AAL45654) and Atu4856 (accession no. AAL45650), in the UW version of $A$. tumefaciens genome (Wood et al. 2001); we designated them VBP2 and VBP3, respectively. The genes encoding them also can be found in the Cereon version of the A. tumefaciens genome (Goodner et al. 2001). In the UW version of the A. tumefaciens genome, the VBP1, VBP2, and VBP3 proteins are predicted to contain 313, 311, and 308 amino acids, respectively (Fig. 3). The three VBPs are highly similar to each other. VBP1 exhibits $72 \%$ identity and $80 \%$ similarity with VBP2; VBP1 shares $56 \%$ identity and $71 \%$ similarity with VBP3 (Fig. 3).

Each of the three VBPs contains a putative nucleotidyltransferase motif in their $\mathrm{N}$-terminal region and a putative higher eukaryotes and prokaryotes nucleotide-binding (HEPN) domain in their C-terminal region (Fig. 3). A very diverse spectrum of proteins may contain a nucleotidyltransferase motif; the substrates of nucleotidyltransferases are extremely diverse (Aravind and Koonin 1999). It remains elusive whether VBPs possess any nucleotidyltransferase activity or how nucleotidyltransferase activity might contribute to the VBP function in tumorigenesis.
Binding between VirD2 and each of the VBPs.

During the initial experiments, the pulled-down proteins were analyzed by using Coomassie blue-stained sodium dodecyl sulfate polyacrylamide gel electrophoresis (SDS-PAGE) and then MALDI-TOF MS. To efficiently detect more interactions, we analyzed the pulled-down proteins by Western blot using VBP antibodies. We used several control fusion proteins to determine whether the binding between VirD2 and VBP1 is specific. One protein cross-reacting with the VBP1 antibody was pulled down by MBP-VirD2 (Fig. 4A, lane 6) and not by amylose resin (lane 2), MBP (lane 3) or MBP-VirJ (lane 4). This protein was not pulled down by MBP-C-VirD2 (lane 5), which is a truncated version of MBP-VirD2 and has only the C-terminal half of VirD2 fused onto VirD2. It appeared that the N-terminal half of VirD2 is important for the interaction. The protein interacting with VirD2 should be identified as VBP1, because MALDI-TOF MS unambiguously identified only VBP1 and not other VBPs in the pull-down samples from the wildtype strain (Figs. 2 and 3). The data suggest that VBP1 could bind to VirD2 specifically.

To confirm the specific interaction between VirD2 and VBP1, we reversed the binding partners and used histidine (His)-VBP1 as the affinity ligand to pull down the native VirD2 protein from AS-induced A. tumefaciens cells. HisKatA fusion protein was used as a negative control, because KatA is a catalase (Xu et al. 2001) and, thus, was not expected to bind VirD2. We used a denaturing buffer to dissolve both His-VBP1 and His-KatA, because most of the His-VBP1 fusion protein overexpressed in Escherichia coli was insoluble (data not shown). The denatured His-VBP1 and His-KatA were allowed to bind to TALON metal affinity resin; then, the denaturant urea and salt were removed. Sub-

\section{Nucleotidyltransferase domain}

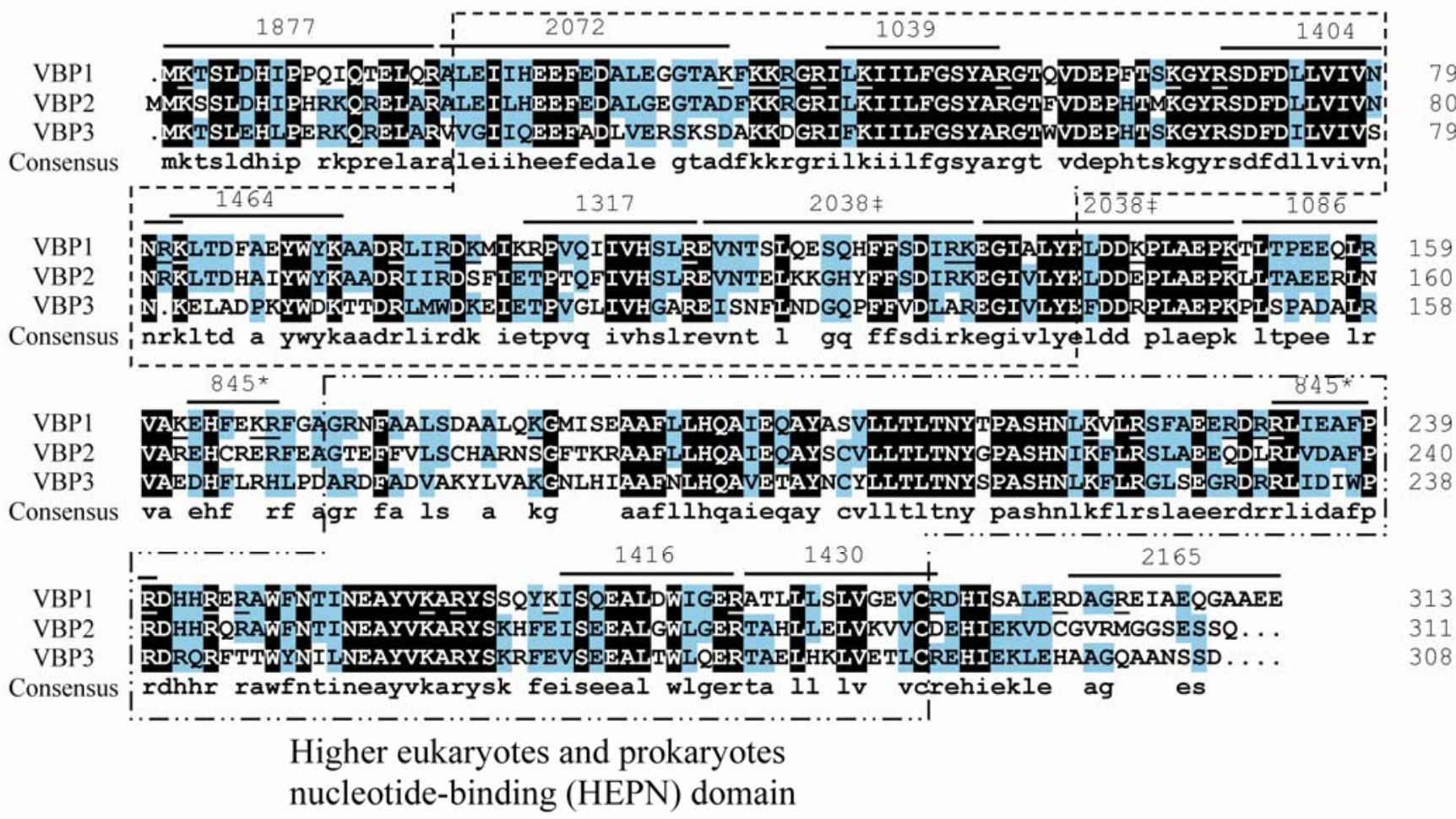

Fig. 3. Sequences comparison of VirD2-binding proteins (VBPs) and coverage map of the matched peptides. The amino acid sequences of VBP1, VBP2, and VBP3 are aligned and compared. Identical amino acids are shaded in black; similar amino acids are shaded in gray. The numbers in the right indicate the amino acid positions. The sequences of three VBP are from the University of Washington version of the genome data (Wood et al. 2001). The matched peptide fragments of VBP1 are indicated by solid lines above the VBP1 sequence. The molecular weights of the corresponding peptides are given above the lines. A pair of peptides having the same molecular weight (845 D) is marked with *; another pair (2038 D) is marked with $\ddagger$. 
sequently, the denatured His-VBP1 and His-KatA were allowed to refold, before they were used to pull down VirD2. Only His-VBP1 could pull down VirD2 (Fig. 4B, lane 2). Therefore, the binding between VBP1 and VirD2 is a specific interaction.

Because VBP2 and VBP3 are highly similar to VBP1, we wanted to determine whether VBP2 and VBP3 have the same function as VBP1. We used His-VBP2 and His-VBP3 to conduct the pull-down assays to test whether VBP2 and VBP3 also could pull down VirD2. Both VBP2 and VBP3 could pull down VirD2 from the protein extract of AS-induced A. tumefaciens cells (Fig. 4C). This showed that both VBP2 and VBP3 also can bind to VirD2, just like VBP1.

\section{Direct interaction between VBP1 and VirD2.}

To determine whether VirD2 interacts directly with the VBPs, we used purified MBP-VirD2 fusion protein to conduct the pull-down assay with purified His-VBP1. Both MBPVirD2 and His-VBP1 were expressed and purified from $E$. coli, which does not contain any $v b p$ homolog gene and was not introduced with any $A$. tumefaciens gene other than $v i r D 2$ or $v b p$. Thus, no potential co-factor or co-factors from A. tumefaciens might contribute to the binding between VirD2 and VBP1 in the pull-down assay. In addition, the proteins were denatured and then purified; and the renatured proteins were used for the binding; any potential co-factor or co-factors from $E$. coli could have been removed. Indeed, no $E$. coli protein was specifically pulled down by VirD2 or VBP in the assays, based on our MALDI-TOF identification. The purified MBP-VirD2 could still bind to the purified HisVBP1 (Fig. 4D, lane 1). This suggests that VirD2 interacts with VBP directly.
A redundantly encoded role of $v b p$ in tumorigenesis.

To test the effect of $v b p$ mutation on bacterial ability to cause tumors, we generated $v b p$ mutants in A. tumefaciens strains A348 and GMI9017. Because vbpl is harbored on the plasmid pAtC58, the effect of $v b p 1$ may be removed by using A. tumefaciens strain GMI9017, which lacks the vbpl-containing plasmid pAtC58 (Rosenberg and Huguet 1984). Therefore, we focused on generating mutations at $v b p 2$ and $v b p 3$ and obtained different $v b p$ mutant strains: AMV2, GMV12, AMV23, and GMV123 (Table 1). We inoculated the $v b p$ mutants and their parent strains onto the leaves of Kalanchoe plants. Only GMV123 that contained no functional $v b p$ gene was highly attenuated in the ability to cause tumors on plants (Fig. 5A). The other three $v b p$ mutant strains, AMV2, GMV12, and AMV23, that contained one or two $v b p$ genes did not show any apparent difference in tumor formation when compared with their parent strains, A348 and GMI9017. This suggests that all three $v b p$ genes, $v b p 1, v b p 2$, and $v b p 3$, could functionally complement each other.

To confirm this, we constructed three plasmids, pCBV1, pCBV2, and pCBV3, which carry the full-length $v b p 1, v b p 2$, and $v b p 3$, respectively, as well as their flanking sequences. We introduced each of these three plasmids into GMV123 (lacking any functional $v b p$ ) to test whether introduction of any single $v b p$ gene could restore the tumorigenicity. Introduction of any single $v b p$ gene indeed fully restored the ability of the $v b p$ triple mutant to cause tumors (Fig. 5B).

To further compare the virulence of GMV123 and its parent strain, GMI9017, we infected Kalanchoe plants with different cell concentrations. GMV123 induced much less and smaller tumors on plants than GMI9017 at a high concentration of $1 \times$ $10^{9}$ cells $/ \mathrm{ml}$ (Fig. 5C). At concentrations of $1 \times 10^{7}$ or $1 \times 10^{8}$
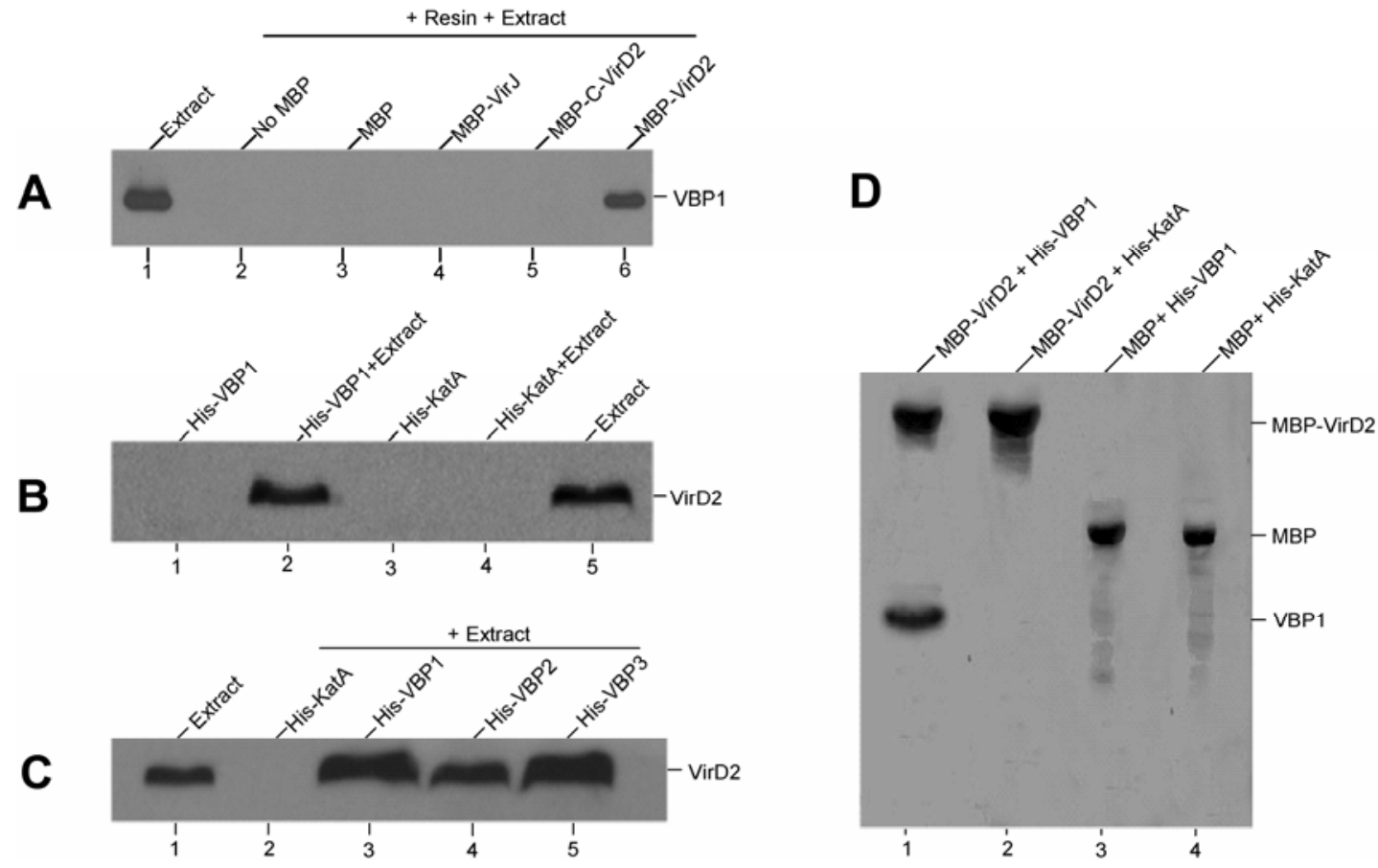

Fig. 4. Binding between VirD2 and each of the VirD2-binding proteins (VBPs). A through $\mathbf{C}$, Proteins indicated on the right were detected by Western blot with rabbit His-VBP1 or His-VirD2 antibody. A, The pull-down assay with maltose-binding protein (MBP) fusion proteins. Protein extract (lane 1) of acetosyringone-induced Agrobacterium tumefaciens cells was pulled down by using amylose resin (lane 2), MBP (lane 3), MBP-VirJ (lane 4), MBP-C-VirD2 (lane 5), or MBP-VirD2 (lane 6). B, Binding between His-VBP1 and VirD2. His-VBP1 (lane 2) and His-KatA (lane 4) were used for the pull-down assay. Purified His-VBP1 (lane 1) and His-KatA (lane 3) were used as the negative controls; protein extract (lane 5) of A. tumefaciens cells was used as a control. C, Pulling down of VirD2 by VBP1, VBP2, or VBP3. His-KatA (lane 2), His-VBP1 (lane 3), His-VBP2 (lane 4), and His-VBP3 (lane 5) were used for the pull-down assay. Protein extract (lane 1) of A. tumefaciens cells was used as a control. D, Binding between VBP1 and VirD2, both purified from Escherichia coli. After purification, MBP-VirD2 (lanes 1 and 2) and MBP (lanes 3 and 4) were used to pull down purified His-VBP1 (lanes 1 and 3) and purified HisKatA (lanes 2 and 4), respectively. The pulled-down proteins were separated by sodium dodecyl sulfate polyacrylamide gel electrophoresis and detected by Coomassie brilliant blue staining. 
cells/ml, GMV123 did not induce any tumors on plants. We wondered if the $v b p$ mutation could affect the growth rate of $A$. tumefaciens cells. Therefore, we compared the growth curves of GMV123 and GMI9017. No significant difference in growth rate was observed between GMV123 and GMI9017 in both rich and minimal media (MG/L and induction broth [IB; Cangelosi et al. 1991]) (data not shown). Therefore, $v b p$ is important for the bacterial virulence to cause tumors on plants; the three $v b p$ genes can functionally complement each other; and the $v b p$ function in tumorigenesis is redundantly encoded in A. tumefaciens.

\section{Clustering of $v b p$ with conjugative transfer genes.}

We determined the genomic locations of VBP-encoding genes based on the genome data. Gene $v b p l$ is located on the plasmid pAtC58; both $v b p 2$ and $v b p 3$ are located on the linear chromosome and very close to each other (Fig. 6). Interestingly, $v b p 1$ is located only $3 \mathrm{~kb}$ away from the conjugative transfer genes (Fig. 6), which are part of the gene clusters for the conjugation of a megaplasmid pAtC58 (Chen et al. 2002). The
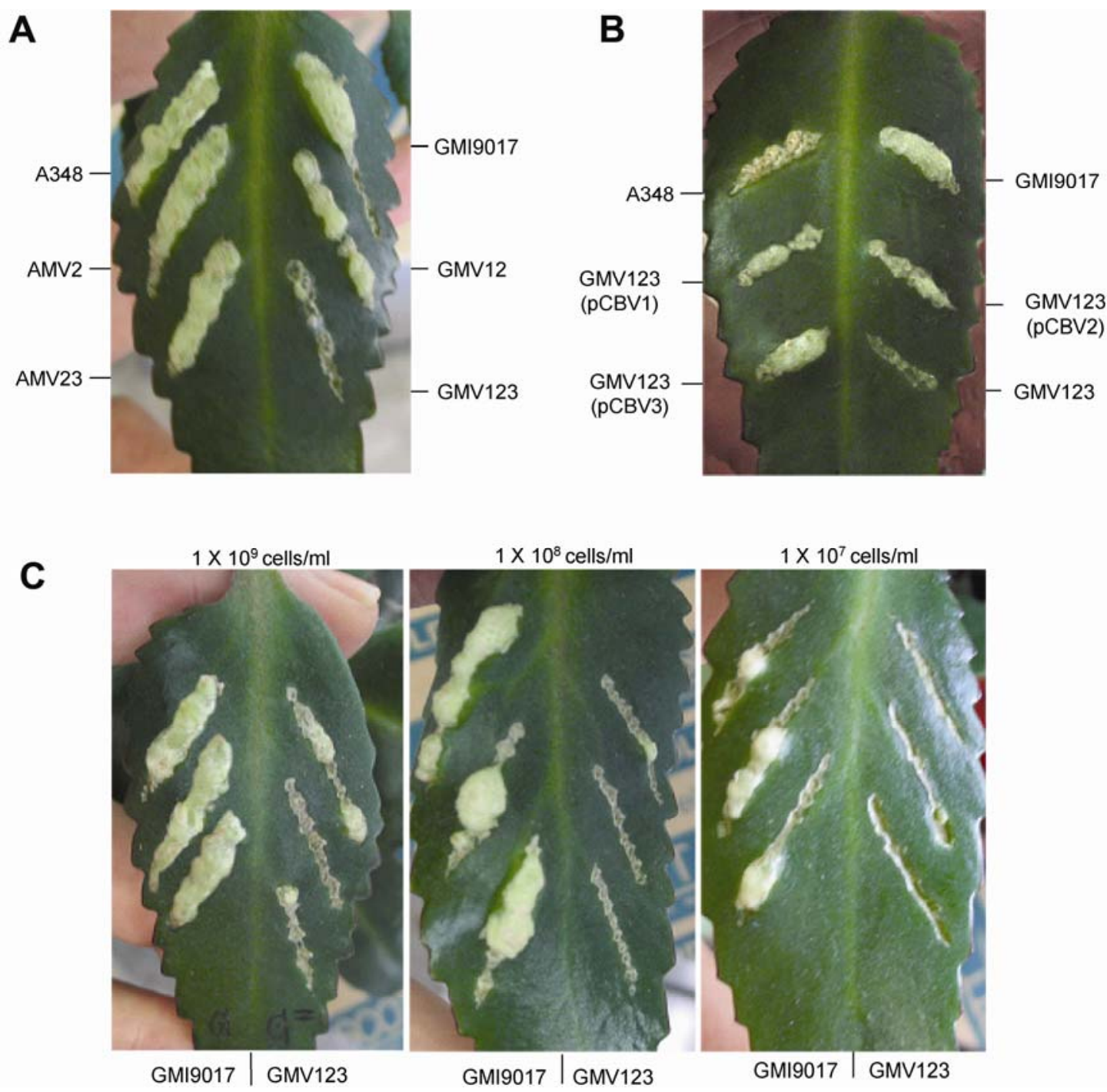

Fig. 5. Effect of $v b p$ mutation on tumorigenesis. Different Agrobacterium tumefaciens strains were grown in MG/L medium (Cangelosi et al. 1991) at $28^{\circ} \mathrm{C}$ for 1 day. The cell concentration was adjusted to $1 \times 10^{9}, 1 \times 10^{8}$, or $1 \times 10^{7}$ cells/ml. Then, $2 \mu \mathrm{l}$ of cell suspension was inoculated onto each wound area on the leaves of Kalanchoe plants. The tumors were photographed 35 to 42 days after inoculation. A, Comparison of A. tumefaciens strains A348, GMI9017, AMV2, GMV12, AMV23, and GMV123 to cause tumors. The leaf inoculated with $1 \times 10^{8}$ cells $/ \mathrm{ml}$ is presented as the representative. B, Complementation of GMV123 (lacking all the three VirD2-binding proteins) by any $v b p$ gene harbored on a plasmid. The leaf inoculated with $1 \times 10^{8}$ cells/ml is presented as the representative. C, The effect of the cell concentrations on the tumorigenesis of GMV123 and GMI9017. The leaves inoculated with different cell concentrations are presented. 
T-strand could not be produced (Table 1). When the total DNA was not digested by $B c l$, more PCR product was generated, presumably because both the ds-Ti-plasmid and ss-T-strand could be used as the templates (lanes 1 to 3 ). Further, less PCR product was amplified from the virD2 mutant GMV123d 2 in the absence of $B c l$ I. The data suggest that our PCR-based method could indicate the abundance of the T-strand in the bacterial cells, although the method is not quantitative. The abundance of the PCR product generated from GMV123 was similar to that from GMI9017 (lanes 4 and 6), indicating that the abundance of T-strand is normal in the $v b p$ triple mutant and VBP is not required for the T-strand production.

\section{VBPs contain clusters}

\section{of positively charged residues at $\mathrm{C}$-termini.}

Because the $v b p$ triple mutant produces a normal level of $\mathrm{T}$ strand in the bacterial cells, the VBP function must be important for the next step of tumorigenesis: the T-DNA transfer. Analysis of the VBP amino acid sequences showed that the three VBPs appear to contain clusters of positively charged residues at their C-termini (Fig. 8), which have been found to be an important common feature shared among T4SS substrates (Christie 2004; Vergunst et al. 2005). The positive-charge clusters are believed to be the transport signals of T4SS substrates and to mediate the interactions between the secretion substrate and VirD4, a component of the A. tumefaciens T4SS apparatus (Christie 2004; Hohlfeld et al. 2006; Vergunst et al. 2005). This suggests that the VBPs might be able to interact with the T4SS apparatus.

\section{DISCUSSION}

VirD2 plays a crucial role in the Agrobacterium-mediated TDNA transfer into plant cells; it participates in the entire transfer process, from the processing to the integration of T-DNA into host plant genome (Gelvin 2000, 2003; McCullen and Binns 2006). Using an MBP-VirD2 fusion protein as the affinity ligand to perform the pull-down assay, we identified a VBP, designated VBP1. Besides vbpl, A. tumefaciens has two additional genes, $v b p 2$ and $v b p 3$, encoding similar proteins. To determine the biological function of $v b p$ genes, we generated mutations at $v b p$. The $v b p$ triple mutant GMV123 that had no

Table 1. Bacterial strains and plasmids used in this study

\begin{tabular}{|c|c|c|}
\hline Bacterial strain and plasmid & Relevant characteristics $^{\mathbf{a}}$ & Source or reference \\
\hline \multicolumn{3}{|l|}{ Strains } \\
\hline \multicolumn{3}{|l|}{ Escherichia coli } \\
\hline $\mathrm{DH} 5 \alpha$ & $\begin{array}{l}\text { EndA1 hsdR17 supE44 thi-1 recA1 gyrA96 relA1 (argF-lacZYA) U169 } \phi 80 \mathrm{~d} l a c Z \text {, for } \\
\text { DNA cloning }\end{array}$ & Bethesda Research Laboratories \\
\hline BL21(DE3) & $F^{-} o m p \mathrm{~T} h s d S_{B}\left(r_{B}{ }^{-} m_{B}{ }^{-}\right)$gal dcm (DE3), for protein expression & Invitrogen \\
\hline \multicolumn{3}{|l|}{ Agrobacterium tumefaciens } \\
\hline C58 & Wild-type, nopaline-type pTiC58 plasmid & Laboratory collection \\
\hline A348 & Wild-type, A136 (pTiA6NC) (octopine-type) & Knauf and Nester 1982 \\
\hline GMI9017 & $\mathrm{C} 58$ cured of pAtC58; lacking $v b p 1 ; \mathrm{Sm}^{\mathrm{r}}, \mathrm{Sp}^{\mathrm{r}}, \mathrm{Rf}^{\mathrm{R}}$ & Rosenberg and Huguet 1984 \\
\hline GMV12 & Derivative of GMI9017 in which $v b p 2$ was deleted & This study \\
\hline GMV123 & Derivative of GMI 9017 in which $v b p 2$ and $v b p 3$ were mutated; $\mathrm{Cb}^{\mathrm{r}}$ & This study \\
\hline GMV123d2 & Derivative of GMI9017 in which $v b p 2, v b p 3$ and $v i r D 2$ were mutated; $\mathrm{Cb}^{\mathrm{r}}$ & This study \\
\hline AMV2 & Derivative of A348 in which $v b p 2$ was deleted & This study \\
\hline AMV23 & Derivative of A348 in which $v b p 2$ and $v b p 3$ were mutated; $\mathrm{Cb}^{\mathrm{r}}$ & This study \\
\hline \multicolumn{3}{|c|}{ 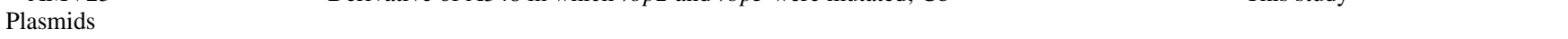 } \\
\hline pUC19 & Cloning vector, ColE1 oriV bla; $\mathrm{Ap}^{\mathrm{r}}$ & U.S. Biochemical \\
\hline pEX18Tc & Counterselectable plasmid carrying sacB marker, oriT; $\mathrm{Tc}^{\mathrm{r}}$ & Hoang et al. 1998 \\
\hline pCB301 & A mini binary vector; $\mathrm{Km}^{\mathrm{r}}$ & Xiang et al. 1999 \\
\hline pQM118 & Derivative of $\mathrm{pEX} 18 \mathrm{Tc}$ in which $\mathrm{Tc}^{\mathrm{r}}$ was replaced by $n p t \mathrm{III}$ from $\mathrm{pCB} 301 ; \mathrm{Km}^{\mathrm{r}}$ & This study \\
\hline pMAL-cRI & Expression vector encoding the full-length maltose-binding protein (MBP); $\mathrm{Ap}^{\mathrm{r}}$ & New England Biolabs \\
\hline \multirow[t]{2}{*}{ pSQ166 } & pMAL-cRI containing a malE::virD2 fusion encoding MBP-VirD2 with MBP fused onto & \\
\hline & VirD2 at the PstI site of virD2; Ap ${ }^{\mathrm{r}}$ & This study \\
\hline \multirow[t]{2}{*}{ pSQ190 } & pMAL-cRI containing a malE::virJ fusion encoding MBP-VirJ with MBP fused onto & \\
\hline & VirJ at the PstI site of virJ; $\mathrm{Ap}^{\mathrm{r}}$ & This study \\
\hline pSQ203 & pMAL-cRI containing a malE:virD2 fusion encoding MBP-C-VirD2 with MBP fused & This study \\
\hline pXQ15 & $\begin{array}{l}\text { pRSET-A carrying a } 2170 \mathrm{bp} \mathrm{XhoI-KpnI} \mathrm{fragment} \mathrm{encoding} \mathrm{the} \mathrm{full-length} \mathrm{KatA} \mathrm{ORF} \\
\text { fused in-frame with }(\mathrm{His})_{6} ; \mathrm{Ap}^{\mathrm{r}}\end{array}$ & Xu et al. 2001 \\
\hline pEXKm1 & pQM118 carrying at HindIII a 2,183-bp fragment downstream of $v b p 2 ; \mathrm{Km}^{\mathrm{r}}$ & \\
\hline pEXKm2 & pEXKm1 carrying at BamHI a 1,395-bp fragment upstream of $v b p 2 ; \mathrm{Km}^{\mathrm{r}}$ & This study \\
\hline $\mathrm{pEXKd} 2$ & $\begin{array}{l}\text { pQM118 carrying at Bam } \mathrm{HI} \text { a } 1,211-\mathrm{bp} \text { fragment containing the upstream and } \\
\text { downstream sequences of } \operatorname{virD2} ; \mathrm{Km}^{\mathrm{r}}\end{array}$ & This study \\
\hline pUCV3 & $\begin{array}{l}\text { pUC19 carrying at Bam HI a 596-bp fragment encoding N-terminal half of } v b p 3 \text { ORF } \\
\text { without the start code; } \mathrm{Ap}^{\mathrm{r}}\end{array}$ & This study \\
\hline pRV1 & $\begin{array}{l}\text { pRSET-A carrying at XhoI a 947-bp fragment encoding the full-length } v b p 1 \text { ORF fused } \\
\text { in-frame with (His) })_{6} ; \mathrm{Ap}^{\mathrm{r}}\end{array}$ & This study \\
\hline pRV2 & $\begin{array}{l}\text { pRSET-B carrying at } B a m \mathrm{HI}_{\text {a }} 952 \text {-bp fragment encoding the full-length } v b p 2 \mathrm{ORF} \\
\text { fused in-frame with (His) } ; \mathrm{Ap}^{\mathrm{r}}\end{array}$ & This study \\
\hline \multirow[t]{2}{*}{ pRV3 } & pRSET-B carrying at BamHI a 936-bp fragment encoding the full-length $v b p 3$ ORF & \\
\hline & fused in-frame with $(\mathrm{His})_{6} ; \mathrm{Ap}^{\mathrm{r}}$ & This study \\
\hline pCBV1 & $\begin{array}{l}\text { pCB301 carrying at HindIII a 2,054-bp fragment containing the } 941-\mathrm{bp} \text { full-length } v b p 1 \\
\text { ORF as well as its } 597-\mathrm{bp} \text { upstream and 516-bp downstream sequences; } \mathrm{Km}^{\mathrm{r}}\end{array}$ & This study \\
\hline \multirow[t]{2}{*}{ pCBV2 } & pCB301 carrying at HindIII a 2,031-bp fragment containing the 935-bp full-length $v b p 2$ & \\
\hline & ORF as well as its 602-bp upstream and 494-bp downstream sequences; $\mathrm{Km}^{\mathrm{r}}$ & This study \\
\hline \multirow[t]{2}{*}{ pCBV3 } & pCB301 carrying at HindIII a 2,027-bp fragment containing the 926-bp full-length $v b p 3$ & \\
\hline & ORF as well as its 597-bp upstream and 504-bp downstream sequences; $\mathrm{Km}^{\mathrm{r}}$ & This study \\
\hline
\end{tabular}

${ }^{\mathrm{a}} \mathrm{Ap}^{\mathrm{r}}, \mathrm{Cb}^{\mathrm{r}}, \mathrm{Gm}^{\mathrm{r}}, \mathrm{Km}^{\mathrm{r}}, \mathrm{Rf}^{\mathrm{r}}, \mathrm{Sm}^{\mathrm{r}}, \mathrm{Sp}^{\mathrm{r}}$, and $\mathrm{Tc}^{\mathrm{r}}=$ Resistant to ampicillin, carbenicillin, gentamicin, kanamycin, rifampicin, streptomycin, spectinomycin, and tetracycline, respectively; ORF $=$ open reading frame. 
functional $v b p$ gene exhibited attenuated virulence. This strongly indicates that VBP is an additional virulence factor in Agrobacterium tumorigenesis.

Computer analysis revealed that all three VBPs have a putative nucleotidyltrasferase motif and a putative HEPN domain. Nucleotidyltrasferases are classified into more than 10 distinct superfamilies (Aravind and Koonin 1999). The member proteins catalyze a similar chemical reaction: the coupling of nucleoside triphosphates to a free hydroxyl group via elimination of pyrophosphate (Aravind and Koonin 1999). Nucleotidyltransferases are involved in diverse biological functions that range from DNA repair, telomere maintenance, and immunoglobulin gene rearrangement to regulation of biosynthetic pathways and signal transduction (Aravind and Koonin 1999). For instance, protein nucleotidyltransferases, such as protein uridylyl transferases $(\mathrm{GlnD})$ and protein adenylyl transferases (GlnE), could catalyze the nucleotidylation of specific proteins to regulate the functions of the modified proteins (Aravind and Koonin 1999). In view of the diverse spectrum of possible nucleotidyltrasferase activities and substrates, it remains elusive whether any nucleotidyltrasferase activity might be involved in the TDNA transfer.

Interestingly, VBP and its homologs might be part of a DNA transfer and replication (Dtr) system (Fig. 6). Gene $v b p 1$ is located adjacent to conjugative transfer genes for conjugation of a plasmid pAtC58 (Chen et al. 2002). The vbp2 and vbp3 genes are located in the same cluster of genes that are related to conjugation (Leloup et al 2002). A $v b p$ homolog in A. radiobacter $\mathrm{K} 84$ also is clustered with the conjugative transfer genes responsible for the conjugation of plasmid pAgK84 (Kim et al. 2006). Recently, we found that VBP was required for efficient transfer of a conjugative plasmid (M. Guo, unpublished data). These suggest linkage between the conjugative function and virulence factor in A. tumefaciens tumorigenesis.

This is consistent with the accumulating evidence indicating that the processing and transfer of T-DNA from A. tumefaciens to plant cells is similar to the interbacterial conjugation of a variety of plasmids (Lessl and Lanka 1994; Lessl et al. 1992). In both processes, transferred DNA is cleaved at specific cisacting sites (conjugation at oriT and T-DNA transfer at the Tborders) and transferred in a single-stranded form. Like the conjugative relaxase, the protein VirD2 that catalyzes the TDNA scission remains bound to the $5^{\prime}$ end of the T-strand molecule (Lessl and Lanka 1994; Pansegrau et al. 1993).

Plasmid conjugation can be conceptually divided into two function systems: the Dtr system and the mating pair formation (Mpf) system. In the Dtr system, relaxase and auxiliary proteins, which can be host or plasmid encoded, assemble at oriT to form a nucleoprotein complex called the relaxosome. There are extensive sequence similarities between $A$. tumefaciens virB-encoded T4SS apparatus and the Mpf system encoded on plasmids (Christie 2004; Lessl et al. 1992). Conjugative intermediate of plasmid RSF1010 can inhibit A. tumefaciens virulence by competing with the VirD2-T-strand or VirE2 for a common export site (Cascales et al. 2005; Stahl et al 1998).

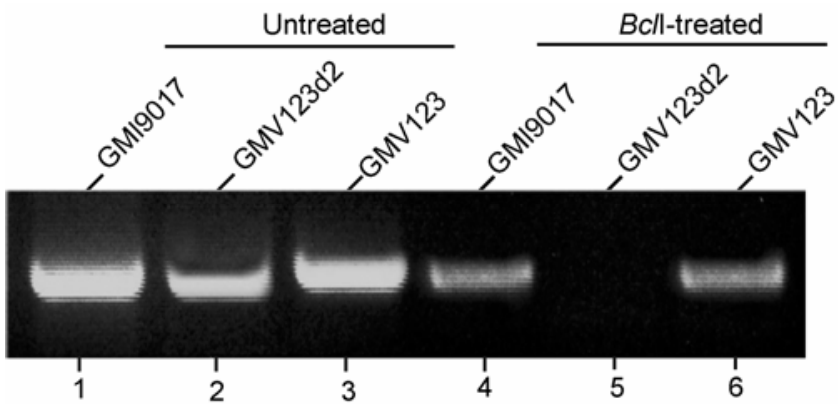

Fig. 7. Detection of the T-strand by polymerase chain reaction. Total DNA was isolated from acetosyringone-induced Agrobacterium tumefaciens GMI9017 (lanes 1 and 4), GMV123d2 (lanes 2 and 5), and GMV123 (lanes 3 and 6) cells. The same concentration of the total DNA was directly used as the template (lanes 1 through 3 ) or digested by $B c l$ I and then used (lanes 4 through 6) to amplify a DNA fragment within the T-strand.

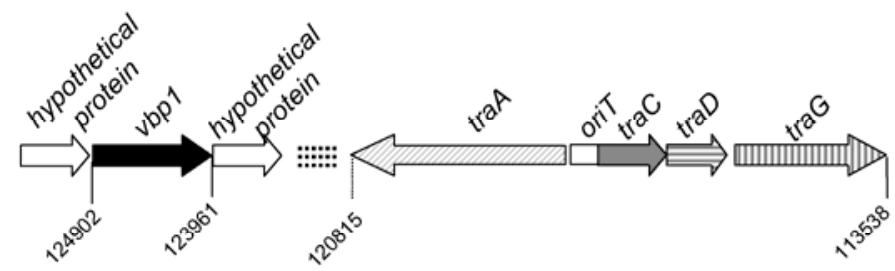

\section{Dtr system of plasmid pAtC58 of Agrobacterium tumefaciens C58 (NC_003306)}
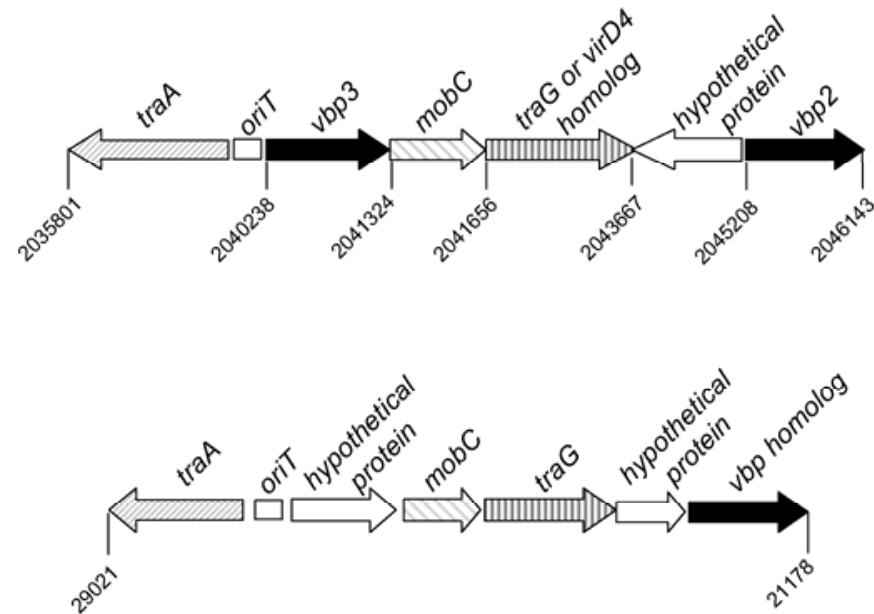

$v b p 2$ and $v b p 3$ on linear chromosome of Agrobacterium tumefaciens C58 (NC_003305)

Fig. 6. Gene organizations in the regions of $v b p$ homologs in Agrobacterium spp. The $v b p$ homologs are shown in black arrows. Genes with significant homology similarity to conjugative transfer genes are shown in filled box arrows of similar patterns. Genes with no significant homology similarity are shown in empty box arrows. The numbers indicate the nucleotide positions in the genomic sequences indicated by the genome Refseq numbers in parenthesis. 
A. tumefaciens virB-encoded T4SS has the capacity to mobilize other relaxosomes (Beijersbergen et al. 1992; Christie et al. 2005). There is extensive evidence for functional relatedness between T-DNA transfer and conjugation (Beijersbergen et al. 1992; Cascales et al. 2005; Lessl and Lanka 1994; Lessl et al. 1992; Stahl et al. 1998).

A protein called the coupling protein $(\mathrm{CP})$ is needed to couple the Dtr to the Mpf in conjugation. The CP determines the recognition between relaxosome and Mpf (Hamilton et al. 2000; Liosa et al. 2003); several CP-relaxase interactions have been demonstrated in vitro. For instances, $\mathrm{TraG}_{\mathrm{RP} 4} \mathrm{CP}$ interacts with $\mathrm{TraI}_{\mathrm{RP} 4}$ relaxase/helicase (Schroder et al. 2002) and with Mob relaxase of the mobilizable plasmid pBHR1 (Szpirer et al. 2000). The $\operatorname{Trw}_{\mathrm{R} 388} \mathrm{CP}$ interacts with $\mathrm{TrwC}_{\mathrm{R} 388}$ relaxase/ helicase; the $\operatorname{TraD}_{\mathrm{F}} \mathrm{CP}$ interacts with $\mathrm{TraM}_{\mathrm{F}}$, a Dtr protein that participates in the processing by binding at sites near oriT of the F plasmid (Disque-Kochem and Dreiseikelmann 1997).

VirD4 is highly similar to TraG of RP4 and functions as a $\mathrm{CP}$ that may link the T-DNA processing system and the mating channel (Backert and Meyer 2006; Christie et al. 2005; Hamilton et al. 2000). However, there is no evidence indicating that the VirD4 CP strongly interacts with the VirD2 relaxase, although the transfer DNA immunoprecipitation showed an in vivo weak interaction between T-DNA and VirD4 (Cascales and Christie 2004). In addition, VirD2 can be transferred to plant cells in the absence of T-DNA (Vergunst et al. 2005). It remains unknown how T-complex is recruited to the transfer apparatus.

As a newly identified virulence factor, VBP is not required for the T-strand production (Fig. 7), suggesting that VBP plays a role in the transfer process subsequent to T-DNA production. The VBPs can bind to VirD2 and they appear to have a common feature shared among T4SS substrates (Fig. 8), suggesting that VBP also may interact with the transfer apparatus, because T4SS substrates pass through the transfer apparatus and the common feature may be involved in the interaction with the apparatus. Because VirD2 is the pilot protein guiding T-DNA transfer, VBP might be involved in the interaction between VirD2 and the transfer apparatus and, thus, is involved in the T-DNA transfer process.

\section{MATERIALS AND METHODS}

Bacterial strains, plasmids, primers, and bacterial cultures.

Bacterial strains and plasmids used in this study are described in Table 1. The sequences of the primers used in this study are described in Table 2. E. coli strains were grown at $37^{\circ} \mathrm{C}$ in Luria-Bertani liquid or agar medium (Sambrook et al. 1989). A. tumefaciens strains were grown at $28^{\circ} \mathrm{C}$ in $\mathrm{MG} / \mathrm{L}$ or IB medium (Cangelosi et al. 1991).

\section{DNA manipulations.}

DNA manipulations followed standard molecular protocols (Sambrook et al. 1989). E. coli DH5 $\alpha$ was used routinely as the host for cloning experiments. E. coli BL21(DE3) was used for protein overproduction. DNA was transferred into $E$. coli cells by heat shock (Sambrook et al. 1989). Plasmids were introduced into A. tumefaciens by electroporation (Cangelosi et al. 1991). Total DNA of A. tumefaciens was prepared according to Charles and Nester (1993).

\section{Preparation of recombinant proteins.}

The plasmids containing genes that encode MBP and MBP fusion proteins MBP-VirD2, MBP-VirJ, and MBP-C-VirD2 (Table 1) were introduced into $E$. coli. The bacterial cells were grown to approximately $5 \times 10^{8}$ cells $/ \mathrm{ml}$; isopropyl $\beta$-D-thiogalactoside (IPTG) was added to the cultures at a final concentration of $0.3 \mathrm{mM}$ to induce expression of the fusion proteins. The bacterial cultures were allowed to grow for additional 2 to $3 \mathrm{~h}$. All the subsequent operations were performed at $4^{\circ} \mathrm{C}$. The cells of $500 \mathrm{ml}$ of culture were harvested by centrifugation and resuspended in $25 \mathrm{ml}$ of lysis buffer $(150 \mathrm{mM} \mathrm{NaCl}, 10 \mathrm{mM}$

\section{Known VirB/D4 T4SS substrates}

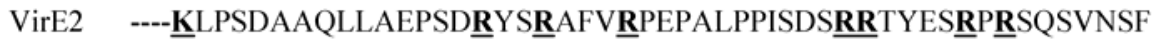

VirE3 ----NSEQQALLNELLSVPLPGPLP白AD

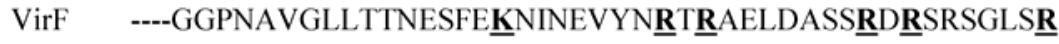

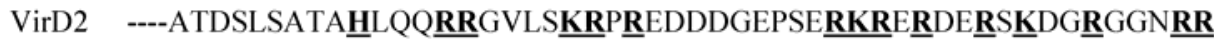

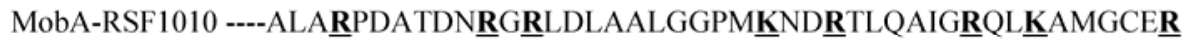

Relaxases known to bind with coupling proteins

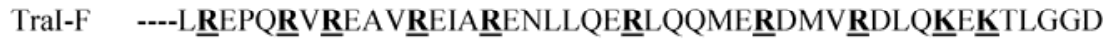

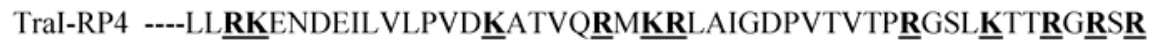

VBP proteins

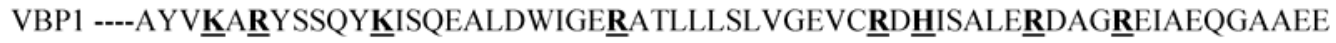

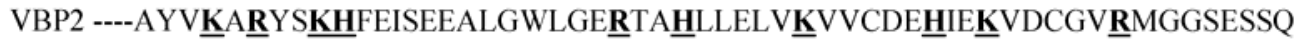

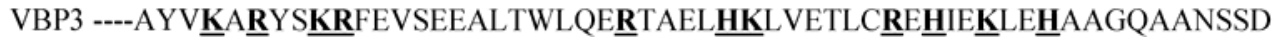

Fig. 8. Three VirD2-binding proteins (VBPs) contain clusters of positively charged amino acid residues at their C termini. Positively charged residues Arg (R), Lys (K), and His $(\mathrm{H})$ were bolded and underlined. This positive charge bias of VBPs is an important common feature found in type IV secretion system (T4SS) substrates, including VirB/D4 T4SS substrates and relaxases that interact with coupling proteins. 
EDTA, $10 \mathrm{mM}$ EGTA, $20 \mathrm{mM}$ Tris, $2 \mathrm{mM}$ dithiothreitol [DTT], $2 \mathrm{mM}$ phenylmethylsulfonyl fluoride [PMSF], $0.25 \%$ Tween-20, leupeptins at $10 \mathrm{mg} \mathrm{liter}^{-1}$, and antipain at $5 \mathrm{mg}$ liter ${ }^{-1}, \mathrm{pH}$ 7.4). The cell suspension was sonicated to near clarity and centrifuged at $17,000 \times g$ for $20 \mathrm{~min}$. Aliquots of the supernatant were stored at $-20^{\circ} \mathrm{C}$. The fusion proteins were purified as described by Pan and associates (1995) with minor modifications. Briefly, $2 \mathrm{ml}$ of amylose resin (New England Biolabs, Beverly, MA, U.S.A.) was washed five times with column buffer (30 mM NaCl, 2 mM EDTA, 2 mM EGTA, 20 $\mathrm{mM}$ Tris, $1 \mathrm{mM}$ DTT, $2.5 \mathrm{mM} \mathrm{MgCl}_{2}, 1 \mathrm{mM}$ PMSF, leupeptins at $2 \mathrm{mg} \mathrm{liter}^{-1}$, and antipain at $1 \mathrm{mg} \mathrm{liter}^{-1}, \mathrm{pH}$ 7.4). Then, $15 \mathrm{ml}$ of $E$. coli lysate, which had been diluted five times from $3 \mathrm{ml}$ of supernatant with $12 \mathrm{ml}$ of column buffer, was added to the amylose resin and incubated for $45 \mathrm{~min}$ with rocking. The protein-bound amylose resin was loaded to a column. The column was washed with $15 \mathrm{ml}$ of column buffer; the bound proteins were eluted with the column buffer containing $10 \mathrm{mM}$ maltose. The purity of the eluted fusion proteins were examined by $10 \%$ SDS-PAGE. The purified fusion proteins were concentrated by Centra-prep and freeze dried.

\section{Pull-down assay for identifying VBPs.}

To prepare A. tumefaciens protein extracts, A348 was grown at $28^{\circ} \mathrm{C}$ in $\mathrm{MG} / \mathrm{L}$ medium for 16 to $18 \mathrm{~h}$. The bacterial cells were collected by centrifugation, washed once with water, and then resuspended to $4 \times 10^{8}$ cells $/ \mathrm{ml}$ in the IB medium containing $200 \mu \mathrm{M}$ AS. The cells were incubated at $28^{\circ} \mathrm{C}$ for another 16 to $18 \mathrm{~h}$ with shaking. The cells were harvested from 5 liters of cell cultures, washed once with water, and resuspended in $15 \mathrm{ml}$ of A. tumefaciens lysis buffer A (30 mM NaCl, 10 $\mathrm{mM} \mathrm{MgCl}_{2}, 5 \mathrm{mM}$ EDTA, $5 \mathrm{mM}$ EGTA, $20 \mathrm{mM}$ Tris, $2 \mathrm{mM}$ DTT, $2 \mathrm{mM}$ PMSF, 1\% Triton X-100, leupeptins at $10 \mathrm{mg}$ liter ${ }^{-1}$, and antipain $5 \mathrm{mg}$ liter $^{-1}, \mathrm{pH}$ 7.4). The cells were disrupted by French Press (cell pressure: $35 \mathrm{~K}$ psi). The protein extract was collected by centrifugation at $12,000 \times g$ for 15 min at $4{ }^{\circ} \mathrm{C}$ and diluted with an equal volume of lysis buffer $\mathrm{A}$ (but without Triton $\mathrm{X}-100$ ). The aliquots of the extract were stored at $-20^{\circ} \mathrm{C}$ until the pull-down assay.

To conduct the pull-down assay, E. coli protein extracts containing MBP, MBP-VirJ, MBP-C-VirD2, and MBP-VirD2 were prepared as described above and allowed to incubate with pre-equilibrated amylose resins $(50 \% \mathrm{vol} / \mathrm{vol})$ for $45 \mathrm{~min}$ at $4{ }^{\circ} \mathrm{C}$ with rocking. Care was taken to ensure that an equal amount of each of the proteins remained bound to the resin. The protein-bound amylose resins were washed with the column buffer. Then, an equal amount of A. tumefaciens protein extract was added to each of the protein-bound amylose resins and incubated for $60 \mathrm{~min}$ at $4{ }^{\circ} \mathrm{C}$ with rocking. The resulting amylose resins were loaded to columns and washed with 6 to 10 column volumes of the column buffer. The bound protein complexes were eluted with the column buffer containing 10 $\mathrm{mM}$ maltose and concentrated by Centra-prep. The concentrated pull-down protein samples were freeze dried and stored at $-20^{\circ} \mathrm{C}$.

\section{In-gel digestion, MALDI-TOF analysis, and tandem MS sequencing.}

All the pull-down protein samples were adjusted to the same protein concentration and separated by 10 or $12 \%$ SDS-PAGE gel. Proteins were excised carefully from Coomassie bluestained gels; the gels were cut into small pieces and then destained with several washes of $50 \mathrm{mM}$ ammonium bicarbonate in $50 \%$ aqueous acetonitrile. The gel pieces were dehydrated with $100 \%$ acetonitrile and dried in Savant Speed-vac. The dried gel pieces were rehydrated with a solution containing $10 \mathrm{mM}$

Table 2. Primers used in this study

\begin{tabular}{|c|c|c|}
\hline Primers & Sequence & Purpose \\
\hline Pvbp1-1 & $5^{\prime}$-ccgctcgagcatgaaacatcgctcg- $3^{\prime}$ & To amplify $v b p 1$ \\
\hline Pvbp1-2 & $5^{\prime}$-ccgctcgagcccgctattcttcag-3' & To amplify $v b p 1$ \\
\hline Pvbp1-3 & $5^{\prime}$-cgctgacgaactacacgccggcg- $3^{\prime}$ & To sequence $v b p 1$ in the expression vector \\
\hline $\mathrm{Pt} 7$ & $5^{\prime}$-aatacgactcactatagg- $3^{\prime}$ & To sequence the genes in pRSET vector \\
\hline Pt7r & $5^{\prime}$-ctagttattgctcagcg- $3^{\prime}$ & To sequence the genes in pRSET vector \\
\hline Pdow3 & $5^{\prime}$-tccaagcttgatcatatcccgcacag-3' & To amplify the downstream sequence of $v b p 2$ \\
\hline Pdow4 & $5^{\prime}$-cccaagcttccagcgcgagtaccag- $3^{\prime}$ & To amplify the downstream sequence of $v b p 2$ \\
\hline Pup10 & $5^{\prime}$-acaggatccettcctgccacgcc- $3^{\prime}$ & To amplify the upstream sequence of $v b p 2$ \\
\hline Pup11 & $5^{\prime}$-gtgggatccatgaactttatacgcttc- $3^{\prime}$ & To amplify the upstream sequence of $v b p 2$ \\
\hline Pscreen 1 & $5^{\prime}$-ctcgagagaggagacgcatcg- $3^{\prime}$ & To screen the $v b p 2$-deletion mutants \\
\hline Pscreen2 & $5^{\prime}$-cagcgcatcctcgaactcctc- $3^{\prime}$ & To screen the $v b p 2$-deletion mutants \\
\hline Pvbp3-1 & $5^{\prime}$-atgggatccagccttgaacatttgcc- $3^{\prime}$ & To amplify a fragment of $v b p 3$ \\
\hline Pvbp3-3 & $5^{\prime}$-gcgggatccactgcctgatgg- $3^{\prime}$ & To amplify a fragment of $v b p 3$ \\
\hline Ppuc1 1 & $5^{\prime}$-cggagcctatggaaaaacgcc- $3^{\prime}$ & To screen $v b p 3$-disrupting mutants \\
\hline Pvbps 1 & $5^{\prime}$-cctctggaatggcccgtacag- $3^{\prime}$ & To screen $v b p 3$-disrupting mutants \\
\hline Pvbps3 & $5^{\prime}$-gaggttgtgcgacgcaggc- $3^{\prime}$ & To screen $v b p 3$-disrupting mutants \\
\hline Pd2du & $5^{\prime}$-ctaggatcccatctgccacgacga- $3^{\prime}$ & To amplify the upstream of $\operatorname{virD2}$ and screen $\operatorname{vir} D 2$-deletion mutant \\
\hline Pd2dul & $5^{\prime}$-ctgaattctggatgatctccttgc-tcagtgctacaaggcgtctttcag-3' & Over-lapping primer; to amplify the upstream of virD2 \\
\hline $\mathrm{Pd} 2 \mathrm{dd}$ & $5^{\prime}$-actggatccttctctatctcctatttc- $3^{\prime}$ & To amplify the downstream of virD2 and to screen for virD2-deletion mutant \\
\hline Pd2ddl & $5^{\prime}$-ctgaaagacgccttgtagcactga-gcaaggagatcatccagaattcag-3' & Over-lapping primer; to amplify the downstream of virD2 \\
\hline Pvbp2p1 & $5^{\prime}$-gatggatccctcccttgatcatatc- $3^{\prime}$ & To amplify $v b p 2$ \\
\hline Pvbp2p2 & $5^{\prime}$-attggatcctgctttgacacctcg-3' & To amplify $v b p 2$ \\
\hline Pvbp3p1 & $5^{\prime}$-catggatcccagccttgaacatttg-3' & To amplify $v b p 3$ \\
\hline Pvbp3p2 & $5^{\prime}$-tgcggatccgtgaagctcaatcg-3' & To amplify $v b p 3$ \\
\hline nptIIIF & $5^{\prime}$-gaagatctctcgagttggcagcatcacc-3' & To amplify nptIII \\
\hline nptIIIR & $5^{\prime}$-gaagatcttactaaaacaattcatccag- $3^{\prime}$ & To amplify $n p t I I I$ \\
\hline Pex18F & $5^{\prime}$-gaagatctgttgaatactcatactcttc- $3^{\prime}$ & To amplify the backbone of pEX18Tc \\
\hline Pex18R & $5^{\prime}$-gaagatcttgtcagaccaagtttactcat-3' & To amplify the backbone of pEX18Tc \\
\hline Pvbp1C1 & $5^{\prime}$-gaggaagcttaaaggatcctcggc- $3^{\prime}$ & To amplify $v b p l$ with its flanking sequence \\
\hline Pvbp1C2 & $5^{\prime}$-gcggaagcttgatgcttggtacg-3' & To amplify $v b p l$ with its flanking sequence \\
\hline Pvbp2C1 & $5^{\prime}$-gatcaagcttccaataattgcggcc-3' & To amplify $v b p 2$ with its flanking sequence \\
\hline Pvbp2C2 & $5^{\prime}$-gtctcaagcttgcgccgatagtg-3' & To amplify $v b p 2$ with its flanking sequence \\
\hline Pvbp3C1 & $5^{\prime}$-ccaaaagcttaaacgcgctgcaag- $3^{\prime}$ & To amplify $v b p 3$ with its flanking sequence \\
\hline Pvbp3C2 & $5^{\prime}$-cgagaagcttgcaaccggttcatg-3' & To amplify $v b p 3$ with its flanking sequence \\
\hline
\end{tabular}


DTT and $100 \mathrm{mM}$ ammonium bicarbonate and incubated at $57^{\circ} \mathrm{C}$ for $60 \mathrm{~min}$ to reduce the disulfide bonds. The reduced sulfhydryl group was alkylated by $55 \mathrm{mM}$ iodoacetamide in $100 \mathrm{mM}$ ammonium bicarbonate at room temperature for 60 min. After alkylation, the gel pieces were washed with $100 \mathrm{mM}$ ammonium bicarbonate solution, dehydrated with $100 \%$ acetonitrile at least six times, and then dried in Savant Speed-vac again. Sequencing grade modified trypsin $\left(12.5 \mathrm{mg} \mathrm{liter}^{-1}\right.$ in $50 \mathrm{mM}$ ammonium bicarbonate, $\mathrm{pH}$ 8.0) was added to the dried gel pieces and incubated overnight at $37^{\circ} \mathrm{C}$. The resulting trypsinized peptides were extracted with $20 \mathrm{mM}$ ammonium bicarbonate solution, $5 \%$ formic acid in $50 \%$ aqueous acetonitrile, and $100 \%$ acetonitrile, respectively. The extracted peptides were combined, lyophilized, and then resuspended in $0.1 \%$ trifluoroacetic acid (TFA). An aliquot of the resuspended peptides was spotted onto the stainless steel MALDI sample plate and overlaid with an equal volume of matrix solution ( $\alpha$-cyano4-hydroxycinnamic acid at $20 \mathrm{~g} \mathrm{liter}^{-1}$ in $0.1 \%$ TFA, and $50 \%$ aqueous acetonitrile). The sample/matrix mixture was allowed to air dry. An Applied Biosystems Voyager-DE STR MALDI mass spectrometer was used to acquire the MALDI-TOF spectra. The instrument was operated in the positive reflector delayed extraction mode. Peptide mass spectra were searched against theoretically derived spectra from proteins in the nonredundant databases of National Center for Biotechnology Information (NCBI) to match peptide mass fingerprints.

Partial amino acid sequence of a single peptide was obtained by Q-TOF hybrid MS/MS. For Q-TOF MS/MS analysis, the trypsinized peptide samples were concentrated and desalted by the Zip-Tip method. Based on the mass spectra acquired by MALDI-TOF, dominant peptides were selected for MS/MS analysis. After peptides were selected, the Q-TOF mass spectrometer was automatically switched from MS to MS/MS mode and the Q-TOF MS/MS spectra were collected. The amino acid sequences were determined by searching the QTOF MS/MS spectra against the NCBI nonredundant protein databases.

\section{Pull-down assay \\ for detecting the binding between VBP and VirD2.}

The full-length $v b p 1, v b p 2$, and $v b p 3$ coding sequences were amplified from $A$. tumefaciens $\mathrm{C} 58$ genomic DNA by PCR and were subcloned into the vector pRSET-A or pRSET-B to make in-frame fusions to the His tag. The resulting plasmids pRV1, pRV2, and pRV3 were introduced to E. coli strain BL21(DE3) to overexpress His-VBP1, His-VBP2, and His-VBP3, respectively. The $E$. coli cells harboring the plasmids were grown and induced by IPTG; they were collected and resuspended in lysis buffer $2(300 \mathrm{mM} \mathrm{NaCl}, 2 \mathrm{mM}$ PMSF, and $50 \mathrm{mM}$ sodium phosphate, $\mathrm{pH}$ 7.4). The cells were disrupted by French Press (cell pressure: $35 \mathrm{~K}$ psi). The pellet was collected by centrifugation at $17,000 \times g$ for $15 \mathrm{~min}$ at $4^{\circ} \mathrm{C}$, resuspended in denaturing column buffer ( $8 \mathrm{M}$ urea, $300 \mathrm{mM} \mathrm{NaCl}, 2 \mathrm{mM}$ PMSF, and $50 \mathrm{mM}$ sodium phosphate, $\mathrm{pH} 7.4$ ), and then incubated at room temperature for $1 \mathrm{~h}$ with shaking. The suspension was centrifuged; the supernatant was collected and then incubated with the pre-equilibrated TALON metal affinity resin (Clontech, Palo Alto, CA, U.S.A.) at room temperature for $1 \mathrm{~h}$. After HisVBP was bound to TALON metal affinity resin, the resin was loaded to a column and washed with 10 to 15 resin volumes of the denaturing column buffer. His-VBP was eluted with the denaturing column buffer plus $150 \mathrm{mM}$ imidazol. The purity of His-VBP was assessed by SDS-PAGE. The purified HisVBPs were injected into rabbits to generate His-VBP antibodies.

To detect the binding between VBP and VirD2, the denaturant urea and salt were removed from the protein-bound resin.
His-VBP-bound resin was washed with buffers having $\mathrm{NaCl}$ gradient from 300 to $0 \mathrm{mM}$ and urea gradient from 8 to $0 \mathrm{mM}$. Eventually, the resin was washed with incubating buffer $(2.5$ $\mathrm{mM} \mathrm{MgCl} 2,50 \mathrm{mM} \mathrm{NaCl}, 2 \mathrm{mM}$ PMSF, leupeptines at $20 \mathrm{mg}$ liter $^{-1}$, and $30 \mathrm{mM}$ Tris-HCl, $\mathrm{pH}$ 7.4). To refold the denatured His-VBP protein, the His-VBP-bound resin was incubated with the incubating buffer at $4^{\circ} \mathrm{C}$ for 60 min with rocking, and then washed three times with the incubating buffer. VirD2-containing A. tumefaciens extract was prepared as described earlier for the pull-down assay for identifying VBPs, except that A. tumefaciens lysis buffer A was replaced by the incubating buffer. His-KatA (Xu et al. 2001) was used as a negative control. The resin-bound VirD2 was eluted with the incubating buffer containing $150 \mathrm{mM}$ imidazol and analyzed by Western blot.

\section{SDS-PAGE and Western analysis.}

SDS-PAGE analysis was performed according to Laemmli (1970). Gels either were stained with Coomassie brilliant blue or processed for Western blot analysis. For Western analysis, proteins were transferred electrophoretically to polyvinylidene difluoride membranes (Bio-Rad, Hercules, CA, U.S.A.) and detected with the ECL Western blotting analysis system (Amersham Life Science, Buckinghamshire, U.K.). Blocking, washing, and exposure were conducted according to the recommendations by the manufacturer. Polyclonal antibodies against His-VirD2 and His-VBP were generated in rabbits and used for the detection.

\section{Generation of A. tumefaciens mutants.}

To delete the $v b p 2$ gene, the $s a c B$-based gene replacement strategy (Hoang et al. 1998) was employed. To obtain a $s a c B$ based suicide vector suitable for A. tumefaciens gene replacement, we replaced the tetracycline-resistant $\left(\mathrm{Tc}^{\mathrm{r}}\right)$ gene of the plasmid pEX18Tc (Hoang et al. 1998) with a kanamycin-resistant $\left(\mathrm{Km}^{\mathrm{r}}\right)$ gene. Primers Pex18F and Pex18R were used to amplify a 5-kb fragment without the $\mathrm{Tc}^{\mathrm{r}}$ gene from pEX18Tc. A $1.04-\mathrm{kb} \mathrm{Km}^{\mathrm{r}}$ cassette fragment was amplified by primers nptIIIF and nptIIIR from plasmid pCB301 (Xiang et al. 1999). These two fragments were ligated to generate the $\mathrm{Km}^{\mathrm{r}}$ plasmid pQM118. The $v b p 2$ gene replacement vector was constructed as follows. First, a 2.183-kb fragment downstream of $v b p 2$ was amplified by primers Pdow3 and Pdow4 and inserted into pQM118 at HindIII to generate plasmid pEXKm1. Then, primers Pup10 and Pup11 were used to amplify a 1.395-kb fragment upstream of $v b p 2$. The upstream fragment was inserted into pEXKm1 at BamHI to produce pEXKm2. The plasmid pEXKm2 was introduced to $A$. tumefaciens cells by electroporation. The cells were plated on kanamycin-containing MG/L agar plates to select for single cross-over transformants. The $\mathrm{Km}^{\mathrm{r}}$ colonies were purified once by streaking on fresh kanamycin-containing MG/L plates, and then were plated on MG/L agar plates containing 5\% sucrose to select for the double cross-over colonies. The $v b p 2$ deletion mutants were identified among the Km-sensitive, sucrose-resistant colonies by PCR. The PCR products were sequenced to confirm that the $v b p 2$ gene was deleted as expected. The $v b p 2$-deletion mutants derived from A348 and GMI9017 were designated AMV2 and GMV12, respectively.

To generate a mutation at $v b p 3$, single cross-over strategy was adopted to disrupt the $v b p 3$ gene (Miller and Mekalanos 1988) because construction of a $v b p 3$ deletion was unsuccessful. A 591-bp $v b p 3$ fragment was amplified from the nucleotide positions 4 to 595 of the $v b p 3$-coding sequence (which is 936 bp) with primers Pvbp3-1 and Pvbp3-3. The fragment was ligated into pUC19 at BamHI to form the ampicillin-resistant plasmid pUCV3. The plasmid then was electroporated into 
A. tumefaciens cells to generate vbp3 insertional mutants due to homologous recombination of the plasmid into the genome. The $v b p 3$ insertional mutants were selected on MG/L agar plates containing carbenicillin and screened by PCR. The PCR products were sequenced to confirm that the plasmid was inserted at the expected site. The $v b p 3$ insertional mutants derived from AMV2 and GMV12 were designated AMV23 and GMV123, respectively.

To generate a virD2 mutant in the $v b p$ triple mutant background, the $s a c B$-based gene replacement strategy (Hoang et al. 1998) was employed as described for the generation of the $v b p 2$ deletion mutant. Primers $\mathrm{Pd} 2 \mathrm{du}$ and $\mathrm{Pd} 2 \mathrm{dul}$ were used to amplify a 522-bp fragment upstream of virD2. Primers Pd2dd and Pd2ddl were used to amplify a 689-bp fragment downstream of virD2. Because primers Pd2dul and Pd2ddl are overlapping primers, the DNA fragments of the two PCR reactions were mixed together as the template and then were used to conduct the second round of PCR by using primers Pd2du and $\mathrm{Pd} 2 \mathrm{dd}$. This generated a $1.211-\mathrm{kb}$ fragment, which contains the upstream and downstream sequences of virD2 but not the 689-bp virD2 coding sequence. This $1.211-\mathrm{kb}$ fragment was inserted into pQM118 at BamHI to generate pEXKd2. The plasmid $\mathrm{pEXKd} 2$ was introduced to GMV123 by electroporation. The virD2 mutant GMV123d 2 then was obtained as described earlier for generating the $v b p 2$ deletion mutants.

\section{Virulence assays.}

A. tumefaciens cells were grown in MG/L liquid medium overnight at $28^{\circ} \mathrm{C}$ supplemented with appropriate antibiotics. The bacterial cells were collected by centrifugation and resuspended in fresh $\mathrm{MG} / \mathrm{L}$ medium. The cell concentrations were adjusted to $1 \times 10^{7}, 1 \times 10^{8}$, and $1 \times 10^{9}$ cells $/ \mathrm{ml}$. The leaves of Kalanchoe plants were wounded with a hypodermic needle. Bacterial cell suspension $(2 \mu \mathrm{l})$ was inoculated onto each wound area. Each strain was inoculated in three different cell concentrations. Each inoculation was repeated at least two times on different leaves. The tumors were photographed 30 to 40 days after inoculation.

\section{Detection of T-strand by PCR.}

Total DNA was isolated from AS-induced A. tumefaciens cells and adjusted to the same concentration based on the absorption at $260 \mathrm{~nm}$. Two primers, which anneal to the ipt gene within the T-DNA of C58, were used to amplify the T-strand. To prevent the ds-Ti-plasmid from acting as the template for this PCR reaction, the total DNA was digested by restriction endonuclease $B c l$ I because the ipt gene fragment contains a $B c l$ site between the two primer sequences. The PCR products were analyzed by electrophoresis.

\section{ACKNOWLEDGMENTS}

This research was supported financially by the National University of Singapore Academic Research Funds (R-154-000-142-112, R-154-000178-422 and R-154-000-208-112). We thank Q. Lin and X. Wang for their technical assistance with the mass spectrometry. We also thank C. Rosenberg for generously providing Agrobacterium tumefaciens GMI9017 strain and S. G. Jin for the donation of plasmid pEX18Tc.

\section{LITERATURE CITED}

Aravind, L., and Koonin, E. V. 1999. DNA polymerase $\beta$-like nucleotidyltransferase superfamily: Identification of three new families, classification and evolutionary history. Nucleic Acids Res. 27:1609-1618.

Backert, S., and Meyer, T. F. 2006. Type IV secretion systems and their effectors in bacterial pathogenesis. Curr. Opin. Microbiol. 9:207-217.

Beijersbergen, A., Dulk-Ras, A. D., Schilperoort, R. A., and Hooykaas, P. J. 1992. Conjugative transfer by the virulence system of Agrobacterium tumefaciens. Science 256:1324-1327.
Bundock, P., Dulk-Ras, A. D., Beijersbergen, A., and Hooykaas, P. J. 1995. Trans-kingdom T-DNA transfer from Agrobacterium tumefaciens to Saccharomyces cerevisiae. EMBO (Eur. Mol. Biol. Organ.) J. 14:3206-3214.

Cangelosi, G. A., Best, E. A., Martinetti, G., and Nester, E. W. 1991. Genetic analysis of Agrobacterium. Methods Enzymol. 204:384-397.

Cascales, E., and Christie, P. J. 2004. Definition of a bacterial type IV secretion pathway for a DNA substrate. Science 304:1170-1173.

Cascales, E., Atmakuri, K., Liu, Z., Binns, A. N., and Christie, P. J. 2005. Agrobacterium tumefaciens oncogenic suppressors inhibit T-DNA and VirE2 protein substrate binding to the VirD4 coupling protein. Mol. Microbiol. 58:565-579.

Charles, T. C., and Nester, E. W. 1993. A chromosomally encoded twocomponent sensory transduction system is required for virulence of Agrobacterium tumefaciens. J. Bacteriol. 175:6614-6625.

Chen, L., Chen, Y., Wood, D. W., and Nester, E. W. 2002. A new type IV secretion system promotes conjugal transfer in Agrobacterium tumefaciens. J. Bacteriol. 184:4838-4845.

Christie, P. J. 2004. Type IV secretion: The Agrobacterium VirB/D4 and related conjugation systems. Biochim. Biophys. Acta 1694:219-234.

Christie, P. J., Atmakuri, K., Krishnamoorthy, V., Jakubowski, S., and Cascales, E. 2005. Biogenesis, architecture, and function of bacterial type IV secretion systems. Annu. Rev. Microbiol. 59:451-485.

Disque-Kochem, C., and Dreiseikelmann, B. 1997. The cytoplasmic DNAbinding protein TraM binds to the inner membrane protein TraD in vitro. J. Bacteriol. 179:6133-6137.

Filichkin, S. A., and Gelvin, S. B. 1993. Formation of a putative relaxation intermediate during T-DNA processing directed by the Agrobacterium tumefaciens VirD1 and VirD2 endonuclease. Mol. Microbiol. 8:915-926.

Gelvin, S. B. 2000. Agrobacterium and plant genes involved in T-DNA transfer and integration. Annu. Rev. Plant Physiol. Plant Mol. Biol. 51:223-256.

Gelvin, S. B. 2003. Agrobacterium-mediated plant transformation: The biology behind the "Gene-Jockeying" tool. Microbiol. Mol. Biol. Rev. 67:16-37

Goodner, B., Hinkle, G., Gattung, S., Miller, N., Blanchard, M., Qurollo, B., Goldman, B. S., Cao, Y., Askenazi, M., Halling, C., Mullin, L., Houmiel, K., Gordon, J., Vaudin, M., Iartchouk, O., Epp, A., Liu, F., Wollam, C., Allinger, M., Doughty, D., Scott, C., Lappas, C., Markelz, B., Flanagan, C., Crowell, C., Gurson, J., Lomo, C., Sear, C., Strub, G., Cielo, C., and Slater, S. 2001. Genome sequence of the plant pathogen and biotechnology agent Agrobacterium tumefaciens C58. Science 294:2323-2328.

Groot, M. J., Bundock, P., Hooykaas, P. J., and Beijersbergen, A. G. 1998. Agrobacterium tumefaciens-mediated transformation of filamentous fungi. Nat. Biotechnol. 16:839-842.

Haase, J., Lurz, R., Grahn, A. M., Bamford, D. H., and Lanka, E. 1995. Bacterial conjugation mediated by plasmid RP4: RSF1010 mobilization, donor-specific phage production, and pilus production require the same Tra2 core components of a proposed DNA transport complex. J. Bacteriol. 177:4779-4791.

Hamilton, C. L., Lee, H., Li, P-L., Cook, D. M., Piper, K. R., Bodman, S. B., Lanka, E., Ream, W., and Farrand, S. K. 2000. TraG from RP4 and TraG and VirD4 from Ti plasmids confer relaxosome specificity to the conjugal transfer system of pTiC58. J. Bacteriol. 182:1541-1548.

Hoang, T. T., Karkhoff-Schweizer, R. R., Kutchma, A. J., and Schweizer, H. P. 1998. A broad-host-range Flp-FRT recombination system for sitespecific excision of chromosomally-located DNA sequences: Application for isolation of unmarked Pseudomonas aeruginosa mutants. Gene 212:77-86.

Hohlfeld, S., Pattis, I., Puls, J., Plano, G. V., Haas, R., and Fischer, W. 2006. A C-terminal translocation signal is necessary, but not sufficient for type IV secretion of the Helicobacter pylori CagA protein. Mol. Microbiol. 59:1624-1637.

Howard, A. E., Zupan, J. R., and Zambryski, P. 1992. The VirD2 protein of Agrobacterium tumefaciens contains a C-terminal bipartite nuclear localization signal: Implications for nuclear uptake of DNA in plant cells. Cell 68:109-118.

Jasper, F., Koncz, C., Schell, J., and Steinbiss, H.-H. 1994. Agrobacterium T-strand production in vitro: Sequence-specific cleavage and $5^{\prime}$ protection of single-stranded DNA templates by purified VirD2 protein. Proc. Natl. Acad. Sci. U.S.A. 91:694-698.

Jayaswal, R. K., Veluthambi, K., Gelven, S. B., and Slightom, J. L. 1987. Double-stranded cleavage of T-DNA and generation of single-stranded T-DNA molecules in $E$. coli by a virD-encoded border-specific endonuclease from Agrobacterium tumefaciens. J. Bacteriol. 169:5035-5045.

Kim, J.-G., Park, B. K., Kim, S.-U., Choi, D., Nahm, B. H., Moon, J. S., Reader, J. S., Farrand, S. K., and Hwang, I. 2006. Bases of biocontrol: Sequence predicts synthesis and mode of action of agrocin 84, the Trojan Horse antibiotic that controls crown gall. Proc. Natl. Acad. Sci. U.S.A. 103:8846-8851 
Knauf, V. C., and Nester, E. W. 1982. Wide host range cloning vectors: A cosmid clone bank of an Agrobacterium Ti plasmid. Plasmid 8:45-54.

Kunik, T., Tzfira, T., Kapulnik, Y., Gafni, Y., Dingwall, C., and Citovsky, V. 2001. Genetic transformation of HeLa cells by Agrobacterium. Proc. Natl. Acad. Sci. U.S.A. 98:1871-1876.

Laemmli, U. K. 1970. Cleavage of structural proteins during the assembly of the head of bacteriophage T4. Nature 227:680-685.

Leloup, L., Lai, E.-M., and Kado, C. I. 2002. Identification of a chromosomal tra-like region in Agrobacterium tumefaciens. Mol. Genet. Genomics 267:115-123.

Lessl, M., and Lanka, E. 1994. Common mechanisms in bacterial conjugation and Ti-mediated T-DNA transfer to plant cells. Cell 77:321-324.

Lessl, M., Balzer, D., Pansegrau, W., and Lanka, E. 1992. Sequence similarities between the RP4 Tra2 and the Ti VirB region strongly support the conjugation model for T-DNA transfer. J. Biol. Chem. 267:2047120480.

Liosa, M., Zunzunegui, S., and Cruz, F. 2003. Conjugative coupling proteins interact with cognate and heterologous VirB10-like proteins while exhibiting specificity for cognate relaxosomes. Proc. Natl. Acad. Sci. U.S.A. 100:10465-10470.

McCullen, C. A., and Binns, A. N. 2006. Agrobacterium tumefaciens and plant cell interactions and activities required for interkingdom macromolecular transfer. Annu. Rev. Cell Dev. Biol. 22:101-127.

Miller, V. L., and Mekalanos, J. J. 1988. A novel suicide vector and its use in construction of insertion mutation: Osmoregulation of outer membrane proteins and virulence determinants in vibrio cholerae requires toxR. J. Bacteriol. 170:2575-2583.

Pan, S. Q., Jin, S., Boulton, M. I., Hawes, M., Gordon, M. P., and Nester, E. W. 1995. An Agrobacterium virulence factor encoded by a Ti plasmid gene or a chromosomal gene is required for T-DNA transfer into plants. Mol. Microbiol. 17:259-269.

Pansegrau, W., Schoumacher, F., Hohn, B., and Lanka, E. 1993. Site-specific cleavage and joining of single-stranded DNA by VirD2 protein of Agrobacterium tumefaciens Ti plasmids: Analogy to bacterial conjugation. Proc. Natl. Acad. Sci. U.S.A. 90:11538-11542.

Piers, K. L., Heath, J. D., Liang, X., Stephens, H. M., and Nester, E. W. 1996. Agrobacterium tumefaciens-mediated transformation of yeast. Proc. Natl. Acad. Sci. U.S.A. 93:1613-1618.

Rosenberg, C., and Huguet, T. 1984. The pAtC58 plasmid of Agrobacterium tumefaciens is not essential for tumor induction. Mol. Gen. Genet. 196:533-536.

Sambrook, J. F., Fritsch, E. F., and Maniatis, T. 1989. Molecular Cloning: A Laboratory Manual, 2nd ed. Cold Spring Harbor Laboratory Press, Cold Spring Harbor, NY, U.S.A.

Scheiffele, P., Pansegrau, W., and Lanka, E. 1995. Initiation of Agrobacterium tumefaciens T-DNA processing: Purified protein VirD1 and VirD2 catalyze site- and strand-specific cleavage of superhelical T-border DNA in vitro. J. Biol. Chem. 270:1269-1276.
Schroder, G., Krause, S., Zechner, E. L., Traxler, B., Yeo, H. J., Lurz, R. Waksman, G., and Lanka, E. 2002. TraG-like proteins of DNA transfer systems and of the Helicobacter pylori type IV secretion system: Inner membrane gate exported substrates? J. Bacteriol. 184:2767-2779.

Stahl, L. E., Jacobs, A., and Binns, A. N. 1998. The conjugal intermediate of plasmid RSF1010 inhibits Agrobacterium tumefaciens virulence and virB-dependent export of VirE2. J. Bacteriol. 180:3933-3939.

Szpirer, C. Y., Faelen, M., and Couturier, M. 2000. Interaction between the RP4 coupling protein TraG and the pBHR1 mobilization protein Mob. Mol. Microbiol. 37:1283-1292.

Tinland, B., Koukolikova-Nicola, Z., Hall, M. N., and Hohn, B. 1992. The T-DNA linked protein VirD2 contains two distinct functional nuclear localization signals. Proc. Natl. Acad. Sci. U.S.A. 89:7442-7446.

Tzfira, T., and Citovsky, V. 2006. Agrobacterium-mediated genetic transformation of plants: Biology and biotechnology. Curr. Opin. Biotechnol. 17:147-154.

Tzfira, T., Rhee, Y., Chen, M-H., Kunik, T., and Citovsky, V. 2000. Nucleic acid transport in plant-microbe interactions: The molecules that walk through the walls. Annu. Rev. Microbiol. 54:187-219.

Vergunst, A. C., Van Lier, M. C., Den Dulk-Ras, A., Grosse Stuve, T. A., Ouwehand, A., and Hooykaas, P. J. 2005. Positive charge is an important feature of the C-terminal transport signal of the VirB/D4-translocated proteins of Agrobacterium. Proc. Natl. Acad. Sci. U.S.A. 102:832837.

Vogel, A. M., and Das, A. 1992. Mutational analysis of Agrobacterium tumefaciens VirD2: Tyrosine 29 is essential for endonuclease activity. J. Bacteriol. 174:303-308.

Vogel, J. P., Andrews, H. L., Wong, S. K., and Isberg, R. R. 1998. Conjugal transfer by the virulence system of Legionella pneumophila. Science 279:873-876

Wood, D. W., Setubal, J. C., Kaul, R., Monks, D. E., Kitajima, J. P., Okura, V. K., Zhou, Y., and Chen, L. et al. 2001. The genome of the natural genetic engineer Agrobacterium tumefaciens C58. Science 294:2317-2323.

Xiang, C., Han, P., Lutziger, I., Wang, K., and Oliver, D. J. 1999. A mini binary vector series for plant transformation. Plant Mol. Biol. 40:711-717.

Xu, X. Q., Li, L. P., and Pan, S. Q. 2001. Feedback regulation of an Agrobacterium catalase gene katA involved in Agrobacterium-plant interaction. Mol. Microbiol. 42:645-657.

Yanofsky, M. F., Porter, S. G., Young, C., Albright, L. M., Gordon, M. P. and Nester, E. W. 1986. The virD operon of Agrobacterium tumefaciens encodes a site-specific endonuclease. Cell 47:471-477.

Zhu, J., Oger, P. M., Schrammeijer, B., Hooykaas, P. J., Farrand, S. K., and Winans, S. C. 2000. The bases of crown gall tumorigenesis. J. Bacteriol. 182:3885-3895.

Zupan, J., Muth, T. R., Draper, O., and Zambryski, P. 2000. The transfer of DNA from Agrobacterium tumefaciens into plants: A feast of fundamental insights. Plant J. 23:11-28. 